\title{
METHODS OF EVALUATING TRANSPORTATION AND LOGISTICS OPERATIONS IN SUPPLY CHAINS
}

\author{
Valery Lukinskiy ${ }^{1}$; Viktor Dobromirov ${ }^{2}$ \\ ${ }^{I}$ National Research University Higher School of Economics (HSE) \\ St. Petersburg, Russia \\ e-mail: lukinskiy@mail.ru \\ ${ }^{2}$ Saint Petersburg State University of Architecture and Civil Engineering \\ Vtoraja Krasnoarmejskaja ul., 4 St. Petersburg, Russia \\ e-mail:vdobro@lan.spbgasu.ru
}

\begin{abstract}
The paper considers some issues related to different approaches to estimation of transport and logistic(s) operations in supply networks; analysis is made of the methods and models of analytical description of those operations; it is shown that the works under consideration have no single approach to their accounting, which makes it impossible to form a model of a simple logistic network including such basic operations as transportation and storage; based on the classical model of Harris-Wilson, six versions have been obtained for a simple supply network showing, in particular, value added to the product price stemming from the previously performed logistic operations as well as restrictions associated with the load capacity (cargo capacity) of the vehicle. The choice of an optimum version of the supply network is made based on the criterion of minimum total costs; there are supplied the examples of calculations for different versions of the developed models enabling estimation of the influence of transport and logistic operations on the efficiency of the supply network.
\end{abstract}

Keywords: Logistics, transport, cost

\section{Introduction}

Transportation is a key logistic function involving removal and relocation of material assets, production in progress, and finished products in vehicles using an established transportation technology.

According to the statistical data, the total logistic costs on the performance of logistic operations in supply networks varies, in different countries, from 10\% (e.g. in the US) to $20 \%$ of the GDP (Singapore, the Russian Federation). A large-scale analysis enables categorizing these expenses by basic components: transportation (40-45\%), storage and stock management (30-40\%), and administrative and managerial functions (up to $15 \%$ ). It is obvious that the reduction of transportation costs is a burning issue which settlement will improve the efficiency of the logistic systems.

A promising solution of the established problem is development of the methodological support including relevant models and methods of evaluating the transport and logistic operations. However, the methods considered in research publications are fragmentary and incomplete while the existing analytical apparatus used for optimizing the costs in transport and logistic systems needs rework and concretization that would take into account the specifics of the supply networks.

Different aspects of transportation can be conditionally divided into two trends.

The first trend includes monographs (textbooks and manuals) devoted to logistics and supply network management (Ballou, 1999; Bowersox, Closs, Cooper, 2009; Jonsson, 2008; Lukinskiy, 2007).

The second trend are collections of scientific papers, some of which parts are prepared by small teams of authors, e.g. (Langevin, Riopel, 2005; Stadier, Kilger, 2005), materials of international conferences (Proceedings of the 24th annual Nordic logistics research network conference, 2012) as well as magazines specializing in logistics and supply network management (Laporte, Toth, Vigo, 2012; Stenger, Schneider, Goeke, 2012; Wong, Lai, Venus Lun, Cheng, 2011; Behrends, Floden, 2012).

Based on the analysis of those sources the following Tab. 1 has been compiled. 
Table 1. Main methods used for controlling transportation in supply chains

\begin{tabular}{|l|l|}
\hline Methods (models) & Main functions and operations involving transportation \\
\hline $\begin{array}{l}\text { Task of choosing (forecast, point-based rating, et.) and } \\
\text { decision making in uncertain (risk) conditions and in } \\
\text { competition (artificial intellect; expert methods, } \\
\text { economic(s) analysis methods, etc.) }\end{array}$ & $\begin{array}{l}\text { Choice of transport development strategy (strategic, tactical, operative). } \\
\text { Choice of the transportation method; type(s) of transport; transport } \\
\text { vehicles (by load capacity, etc.), logistic key performance indicators } \\
\text { (KPI). The planning (of production costs, pricing, tariffs, etc.) and } \\
\text { others. }\end{array}$ \\
\hline $\begin{array}{l}\text { Simulation modelling. } \\
\text { Parameter optimization: }\end{array}$ & $\begin{array}{l}\text { Transport inventory structure, delivery routing (opportune cargo), } \\
\text { rolling stock distribution by routes; operative dispatching and planning; } \\
\text { "Just in time" delivery. Supply chain configuration (storage facilities } \\
\text { and terminals location). } \\
\text { models, transportation task, probability theory, Monte } \\
\text { Carlo method, etc. }\end{array}$ \\
\hline
\end{tabular}

Analysis of Tab. 1 enables drawing the following conclusions:

1. Each work of the first category devotes one to three chapters to transportation in supply networks. Here, some aspects of the transport-related subject are included in other chapters (sections).

2. Identical elements are observed in the issues (factors, aspects) under consideration presented by different sources. Here a certain trend is obvious, characterized by a reduced number of trivial (excessively simple) subjects.

3. It is unnecessary to prove the thesis that "Transportation" embraces many technical, technological, economic, organizational, managerial, juridical, social, ecological and other issues. At the same time, an impression is formed that there is no inherent integrity, i.e. practically there is no interconnection and interrelationship between the issues being considered.

The works of the second category include investigation results related to the goods transportation and delivery in logistic systems:

-- integrated location (routing models and integrated location) (Laporte, Toth, Vigo, 2012; Stenger, Schneider, Goeke et al., 2012);

- optimization of transportation time, for example (Goel, 2012);

- issues of inter-operative, inter-functional, and inter-organizational integration, counter-acting problems in the performance of transportation operations (Wong, Lai, Venus Lun, Cheng et al., 2011);

- the problem of evaluating the impact of transpiration on economic indicators, in particular, the value of logistic costs (Behrends, Floden et al., 2012).

It is important to note that a special feature of this type of work is a wide variety of the scientific apparatus involved as well as the preference given to active employment of modern information and computing technologies.

Thus, the review of a number of literary sources suggests that at present there is no single approach to description of and evaluating the methods applied to transport logistic operations in supply networks, which makes it impossible to form a fully adequate analytical model with its subsequent analysis and development of the decision making procedure.

\section{Methodological basis of investigation}

For the methodological basis of forming a package of evaluations of decisions taken in managing transport and logistic operations in the supply network it makes sense to use the general principles of a systematic approach.

Firstly, according to the integrity principle, all the variety of models and methods of transport management, as well as the factors taken into consideration in decision-making, must be based on the established connections showing the interrelationship and mutual influences, which is a particularly difficult task.

Secondly, the analytical methods of evaluation must be separated from the local purposes of supply networks or their individual elements since they require formation and employment of different technologies of managerial decisions support.

Thirdly, the package of the evaluating methods formed must be based on the scientific approaches envisioning a permanent study of new regularities and their practical testing, i.e. implementation of the principle of scientific substantiation and optimality.

Fourthly, the methods of evaluating transport and logistic operations are grouped as independent decisions. So each decision makes it possible to form a managerial decision of a relevant level. The availability of alternative decisions and their analysis will improve the veracity and accuracy of the estimations. 


\section{Analysis and formation of methods of evaluating transport and logistic operations}

Given that at present there are several versions of describing transport and logistic operators included in the model of total logistic costs (TLC), let's consider some of them at a greater length.

First version. The total spending on the order $\left(C_{0}\right)$ and storage $\left(C_{s}\right)$ is considered separately from the spending on transportation $\mathrm{C}_{\mathrm{t}}$. In this case, the optimum order size $\mathrm{S} 0$ is determined by the EOQ model of Harris-Wilson:

$\mathrm{C}_{\Sigma}=\frac{\mathrm{AC}_{0}}{\mathrm{~S}}+\mathrm{C}_{\mathrm{p}} \mathrm{fS} \longrightarrow \min$

i.e.:

$S_{0}=\sqrt{\frac{2 A C_{0}}{C_{p} f}}$

where $\mathrm{A}$ is the yearly demand for products;

$\mathrm{C}_{0}$ are costs associated with the performance of the order for products;

$\mathrm{C}_{\mathrm{p}}$ is the cost of product unit;

$\mathrm{f}$ is a share of cost from the price of the product unit related to the storage cost.

Then the transportation cost will be calculated according to the following formula:

$\mathrm{C}_{\mathrm{t}}=\frac{\mathrm{AC}_{\mathrm{t}}}{\mathrm{S}_{0}}$

The equation of total costs is presented as:

$\mathrm{Ctc}=\mathrm{C} \Sigma+\mathrm{Ct}$

The second version implies inclusion of costs associated with the goods transportation $(\mathrm{Ct})$ in the structure of spending on the performance of the order $\mathrm{C} 0$. In this case the total costs model will be presented as follows:

$\mathrm{C}_{\Sigma}=\frac{\mathrm{AC}_{0}}{\mathrm{~S}}+\frac{\mathrm{AC}_{\mathrm{t}}}{\mathrm{S}}+\frac{\mathrm{C}_{\mathrm{p}} \mathrm{fS}}{2}$.

Then, according to EOQ model, the optimum order value will amount to:

$S_{0}=\sqrt{\frac{2 A\left(C_{0}+C_{t}\right)}{C_{p} f}}$,

while the minimum total costs will be:

$C_{\sum \min }=\sqrt{2 A\left(C_{0}+C_{t}\right) C_{p} f}$.

The third version implies that the spending on transportation is presented as a separate summand in the equation of total logistic costs not related to the optimum lot of delivery and, hence, looks as follows:

$\mathrm{C}_{\Sigma}=\frac{\mathrm{AC}_{0}^{*}}{\mathrm{~S}}+\frac{\mathrm{AE}}{\mathrm{FH}_{\mathrm{H}}}+\mathrm{C}_{\mathrm{p}} \mathrm{fS} \longrightarrow \min$,

where $\mathrm{C}_{0}{ }^{*}$ is spending on the order performance;

$\mathrm{E}$ is a charge for transportation of a single order lot;

$\mathrm{F}_{\mathrm{H}}$ - is a rated cargo capacity (load capacity) of a vehicle.

Fourth version. For some types of transportation, for instance, international, the spending on transportation exceeds other types of expenses in the supply chain, for example, on the order organization and storage.

In this case, the expression for the total cost is structurally similar to the third version, but the formula for Ctc. is presented as follows:

$\mathrm{C}_{\mathrm{cc}}=\frac{\mathrm{A}\left(\mathrm{C}_{0}+\mathrm{E}\right)}{\mathrm{F}_{\mathrm{A}}}+\mathrm{C}_{p} \mathrm{fF}_{\mathrm{A}}$.

where $\mathrm{F}_{\mathrm{A}}$ is a rated cargo capacity (load capacity) of the vehicle expressed in the units of measuring the total demand for the scheduled period. 
The fifth version implies singling out the transportation costs as a separate equation for the period being evaluated:

$C_{t}=\frac{A}{S} E$

The main equation of the summarized spending is presented as:

$\mathrm{C}_{\varepsilon}=\frac{\mathrm{AC}_{0}}{\mathrm{~S}}+\left(C_{p}+\Delta C_{t}\right) \cdot \frac{f S}{2} \rightarrow \min$

$\Delta_{\mathrm{C}_{\mathrm{t}}}=\frac{\mathrm{C}_{\mathrm{t}}}{\mathrm{Sj}}$ - is the added cost of transportation of each product unit.

Thus the equation system can be presented as:

$\left\{\begin{array}{l}\mathrm{C}_{\Sigma}=\frac{\mathrm{AC}_{0}}{\mathrm{~S}}+\left(\mathrm{C}_{\mathrm{p}}+\frac{\mathrm{C}_{\mathrm{t}}}{\mathrm{S}_{\mathrm{j}}}\right) \frac{\mathrm{f} \mathrm{S}}{2} \\ \Delta \mathrm{C}_{t}=\frac{\mathrm{C}_{\mathrm{t}}}{\mathrm{Sj}} \\ \mathrm{C}_{t c}=\mathrm{C}_{\Sigma}+\mathrm{C}_{\mathrm{t}}\end{array}\right.$

A special feature of the system (Eq. 12) is that it shows the dynamics of the processes taking place and their difference in time, i.e. the sequence of the operation performance: order execution, product transportation, and goods storage.

The sixth version is similar to the previous one, but the added cost $\Delta \mathrm{C}$ includes the transportation and the order related expenses.

Tab. 2 presents the calculating formulas for six versions of identifying transportation costs in the total logistic cost model.

Table 2. Systematic approach to evaluating transport and logistic costs in the TLC

\begin{tabular}{|c|c|c|}
\hline № & Total cost equation & Brief description \\
\hline 1 & $\mathrm{C}_{\Sigma}=\frac{\mathrm{AC}_{0}}{\mathrm{~S}}+\mathrm{C}_{\mathrm{p}} \mathrm{fS} \longrightarrow \min$ & $\begin{array}{l}\text { EOQ model taking into account spending } \mathrm{C}_{0} \text { on preparation } \\
\text { (production) of the delivery lot. } \\
\text { Transportation costs are omitted. }\end{array}$ \\
\hline 2 & $\mathrm{C}_{\Sigma}=\frac{\mathrm{AC}_{0}}{\mathrm{~S}}+\frac{\mathrm{AC}_{t}}{\mathrm{~S}}+\frac{\mathrm{C}_{\mathrm{p}} \mathrm{fS}}{2}$ & $\begin{array}{l}\text { Separate account of spending on order organization, storage, and } \\
\text { transportation. }\end{array}$ \\
\hline 3 & $C_{\Sigma}=\frac{A C_{0}^{*}}{S}+\frac{A E}{F_{H}}+C_{p} f S \rightarrow \min$ & $\begin{array}{l}\text { Transportation costs are included in the total equation, but do not } \\
\text { depend on } \mathrm{S}_{0} \text { value (debatable version). }\end{array}$ \\
\hline 4 & $C_{\Sigma}=\frac{A\left(C_{0}+E\right)}{F_{A}}+C_{p} f F_{A} \rightarrow \min$ & $\begin{array}{l}\text { Total logistic cost in using the rated (maximum load) capacity } \\
\text { vehicle without optimization. }\end{array}$ \\
\hline 5 & $\left\{\begin{array}{l}\mathrm{C}_{\Sigma}=\frac{\mathrm{AC}_{0}}{\mathrm{~S}}+\left(\mathrm{C}_{\mathrm{p}}+\frac{\mathrm{C}_{\mathrm{t}}}{\mathrm{S}_{\mathrm{j}}}\right) \frac{\mathrm{fS}}{2} \\
\Delta \mathrm{C}_{t}=\frac{\mathrm{C}_{\mathrm{t}}}{\mathrm{Sj}} \\
\mathrm{C}_{t c}=\mathrm{C}_{\Sigma}+\mathrm{C}_{\mathrm{t}}\end{array}\right.$ & $\begin{array}{l}\text { EOQ integrated model taking into account the transportation cost } \\
\text { in the form of the value added to the product price in considering } \\
\text { the storage costs. }\end{array}$ \\
\hline 6 & $\left\{\begin{array}{l}\frac{A\left(C_{0}+C_{t}\right)}{\mathrm{S}}+\left(\mathrm{Cn}_{\mathrm{n}}+\Delta C_{t}\right) \frac{\mathrm{fS}}{2} \rightarrow \mathrm{min} \\
\Delta \mathrm{C}_{t}=\frac{C_{0}+C_{t}}{\mathrm{Sj}}\end{array}\right.$ & $\begin{array}{l}\text { EOQ integrated model taking into account the transportation and } \\
\text { order costs cost in the form of the value added to the product price } \\
\text { and considering the storage costs }\end{array}$ \\
\hline
\end{tabular}




\section{Testing}

The developed approach enables calculating and choosing the optimum version of organizing a simple supply chain based on the criterion of total costs. For illustration, let us consider an example of the "supplier - consumer" network at the following start-up data: $A=2000$ units, $C_{p}=600$ rubles/unit, $C_{0}=2000$ rubles/order; $\mathrm{C}_{\mathrm{t}}=12000$ rubles/delivery; $\mathrm{F}_{\max }=500$ units; $\mathrm{C}_{\mathrm{s}}=120$ rubles/unit per year. Tab. 3 shows the calculation results.

Analysis of the table shows that version 5 can be realized at the simultaneous shipment of the order by two vehicles; version 4 (transportation with maximum load $\mathrm{F}=500 \mathrm{pcs}$ ) minimizes the total costs while the order and transportation are paid separately, possibly via (through) outsourcing of the vehicle.

Table 3. The results of calculating the costs of different versions of organizing the transportation

\begin{tabular}{|c|c|c|c|c|c|}
\hline \multirow[t]{2}{*}{ Version } & \multirow[t]{2}{*}{ Delivery lot } & \multicolumn{4}{|c|}{ Costs, thousands of rubles } \\
\hline & & $\mathrm{C}_{0 \Sigma}$ & $\mathrm{Cs}_{\Sigma \Sigma}$ & $\mathbf{C}_{\mathrm{t} \Sigma}$ & $\mathbf{C}_{\Sigma}$ \\
\hline 1. EOQ (without transportation) & 258 & 15.5 & 15.5 & - & 31.0 \\
\hline 2. EOQ (including transportation) & 258 & 15.5 & 15.5 & 96.0 & 127.0 \\
\hline 3. Transportation with Fmax & 500 & 8.0 & 30.0 & 48.0 & 86.0 \\
\hline 4. EOQ (at $\left.\mathrm{C}_{0}+\mathrm{E}\right)$ & 930 & 53.6 & 53.6 & Considering in $\mathrm{C}_{0}$ & 197.0 \\
\hline 5. EOQ (with value added during storage) & 213 & 18.7 & 18.7 & 112.7 & 150.1 \\
\hline 6. EOQ (at $\Delta \mathrm{C}_{\mathrm{t}}=\mathrm{C}_{0}+\mathrm{C}_{\mathrm{t}}$ ) & 627 & 6.4 & 44.6 & 38.0 & 89.2 \\
\hline
\end{tabular}

\section{Conclusions}

The study of the specifics of the logistic processes taking place in the supply network made it possible to formulate a hypothesis of the need for their combined consideration in determining the values of the total logistic costs, which is caused by their interconnection and mutual influence.

Analysis of logistic processes makes it possible to describe their special features as morphological multitudes. At the follow-on stages of formation of the methodological approach to controlling the logistic processes in supply networks it is advantageous to use the provisions of the morphological analysis and synthesis, which allows justifiable reduction of the initial symptomatic space and forms classes of models described by similar combinations of the considered signs of logistic processes in the TLC model.

The costs associated with the product transportation play a special role in the total logistic costs, due to which it is necessary to specify calculating formulas for the models of identifying transport costs in TLC.

\section{References}

1. $\quad$ Ballou, R.N. (1999) Business Logistics Management. Prentice-Hall International, Inc. p.681.

2. Behrends, S., Floden, J. (2012) The effect of transshipment costs on the performance of intermodal line-trains Logistics Research, 4-2(3-4), 127-136.

3. Bowersox, D.J., Closs, D.J., Cooper, M.B. (2009) Supply Chain Logistics Management. McGrawHill, p.498.

4. Goel, A. (2012) The minimum duration truck driver scheduling problem. EURO Journal of Transportation and Logistics, 1(4), 285-306.

5. Jonsson, P. (2008) Logistics and Supply Chain Management. London et al: McGraw-Hill, p.491.

6. Langevin, A., Riopel, D. (2005) Logistics Systems: Design and Optimization. Springer Science + Business Media, p.387.

7. Laporte, G., Toth, P., Vigo, D. (2012) Vehicle routing: historical perspective and recent contribution. EURO Journal of Transportation and Logistics, 2(1-2), 1-4.

8. Lukinskiy, V.S. (2007) Models and methods of the logistics. St. Petersburg: Piter, p.448.

9. Proceedings of the 24th annual Nordic logistics research network conference (2012)

10. Stadier, H., Kilger, C. (2008) Supply Chain Management and Advanced Planning: Concept, Models, Software and Case Studies. Springer: Fourth Edition, p.556.

11. Stenger, A., Schneider, M., Goeke, D. (2012) The prize-collecting vehicle routing problem with single and multiple depots and non-linear cost. EURO Journal of Transportation and Logistics, 1(1-2), 57-87.

12. Wong, C.W.Y., Lai, K.-H., Venus Lun, Y.H., Cheng, T.C.E. (2011) A study on the antecedents of supplier commitment in support of logistics operations. International Journal of Shipping and Transport Logistics, 3(3), 5-21. 